\title{
Ecology and life histories of two Alpine-Apenninic species of Velia (Hemiptera: Heteroptera: Veliidae)
}

\author{
FABIO CIANFERONI ${ }^{1,2}$ and GIACOMO SANTINI ${ }^{1}$ \\ ${ }^{1}$ Department of Evolutionary Biology “Leo Pardi”, University of Florence, Via Romana 17, I-50125 Florence, Italy; \\ e-mails: fabio.cianferoni@unifi.it; giacomo.santini@unifi.it \\ ${ }^{2}$ Natural History Museum of the University of Florence, Zoological Section "La Specola", Via Romana 17, I-50125 Florence, Italy
}

Key words. Velia, Gerromorpha, wing polymorphism, co-occurrence, life history

\begin{abstract}
Velia currens (Fabricius, 1794) and V. gridellii Tamanini, 1947 are two South European species of Veliidae, whose ecology and behaviour are poorly known. The aims of this study were to investigate their life histories, quantify occurrence of wing polymorphism and gather information on their degree of co-occurrence. Nine different populations were regularly surveyed from April to November 2010. Furthermore, a dataset containing information on the occurrence of the two species and the presence of winged morphs at 294 sites was compiled from museum collections, private collections and published literature. No evidence for multivoltinism was detected in either species. However, oviposition and and/or hatching were protracted in time so that early-instar nymphs and adults co-occurred up to midsummer. Although their distributional ranges completely overlap at a large spatial scale, the two species co-occurred only rarely at the same sites and the degree of co-occurrence was lower than expected by chance. Winged specimens were rarely recorded. At least in $V$. gridellii, the numbers of winged individuals were inversely related to the altitudes of the sites. During the summer, when some of the streams surveyed dried up, several specimens were found in an apparent state of lethargy, under stones. It is hypothesized that the ability to aestivate, coupled with the ability to walk from one site to another may reduce the advantage associated with producing winged forms and account for the low rate of occurrence of macropterism in these species.
\end{abstract}

\section{INTRODUCTION}

Semi-aquatic bugs (Hemiptera: Heteroptera: Gerromorpha) have highly diverse life cycles and life histories, a feature that has attracted numerous studies in the past (see e.g. Andersen, 1982; Ditrich \& Papáček, 2009a, c). Gerromorpha are recorded to be both uni- and polyvoltine (Andersen, 1982). In temperate areas some species are strictly univoltine (e.g., some Gerris spp.: Mitis, 1937; Brinkhurst, 1959; Vepsäläinen, 1974) or multivoltine (e.g., some Microvelia spp.: Tamanini, 1979; Ditrich \& Papáček, 2009c), but several species may be either uni- or polyvoltine, depending on environmental conditions (e.g. temperature or photoperiod: Vepsäläinen, 1974). If multivoltine, up to three generations have been hypothesized (e.g. Ditrich \& Papáček, 2009c).

A particular feature of the life history of Gerromorpha is wing polymorphism, which consists of the simultaneous occurrence, within the same species, of two or more phenotypes (morphs) that differ in terms of the development of their flight apparatus (Andersen, 1982). Although this phenomenon is documented for several species of Gerromorpha (e.g. Brinkhurst, 1959; Andersen, 1973, 1982, 1993; Vepsäläinen, 1973, 1974, 1978a) it is still not fully understood and several possible determinants are proposed in the literature. Although it is postulated that the development of winged morphs is genetically controlled (e.g. Spence \& Andersen, 1994), the occurrence of this morph is known to depend upon environmental factors, such as photoperiod and temperature (e.g. Muraji et al., 1989; Spence, 1984; Pfenning et al., 2008). In addition, the incidence of winged morphs is usually associated with different degrees of habitat stability (see Andersen, 1993; Ditrich \& Papáček, 2009b and references therein). The observation that the frequency of winged specimens tends to increase as habitats become less predictable in both space and time led to the idea that winged individuals enable species to disperse in patchy/unstable habitats (Brinkhurst, 1959; Socha \& Zemek, 2003). Other factors, including population density and food availability, are also thought to affect the induction of winged forms (e.g. Muraji \& Nakasuji, 1988; Muraji et al., 1989; Harada et al., 1997; Pfenning et al., 2007; Ditrich \& Papáček, 2010b).

Among the West Palaearctic Gerromorpha, the most widely studied family, both in terms of life histories and wing polymorphism, is Gerridae (see Spence \& Andersen, 1994 and Ditrich \& Papáček, 2009a for reviews), whereas other families, such as Veliidae, received less attention until recently (Ditrich et al., 2008, 2011; Ditrich \& Papáček, 2009a, b, 2010a, b; Ditrich \& Koštál, 2011). Furthermore, most of the available information on Veliidae, refers to species in Northern and Central Europe (e.g. Mielewczyk, 1980; Murray \& Giller, 1991), while little or nothing is known about more southern taxa. For example, the data available in the literature on wing polymorphism in the genus Velia are almost exclusively for the centralnorthern European species Velia caprai Tamanini, 1947 (e.g. Brinkhurst, 1959; Ditrich \& Papáček, 2009b). 
TABLE 1. Major environmental features of the nine sites sampled. "Water permanence" indicates whether during the study period a stream completely ran dry (temporary) or not (permanent). "Streambed" and "Banks" indicate the dominant type of substrate at the bottom and on the banks of a stream, respectively. "Sun exposure" indicates whether a site was exposed to direct sunlight (sun) or not (shadow), for most of the day. "Habitat" is the type of environment surrounding each site sampled. Average water and air temperatures recorded during the study period are also provided, together with their minimum and maximum values.

\begin{tabular}{|c|c|c|c|c|c|c|c|c|c|c|c|}
\hline Code & $\begin{array}{c}\text { Geogr. coordinates } \\
\text { UTM WGS84 } \\
\text { (East North) }\end{array}$ & $\begin{array}{l}\text { Altitude } \\
\quad(\mathrm{m})\end{array}$ & $\begin{array}{l}\text { Width } \\
\text { (m) }\end{array}$ & $\begin{array}{l}\text { Depth } \\
(\mathrm{cm})\end{array}$ & $\begin{array}{c}\text { Water } \\
\text { perma- } \\
\text { nence }\end{array}$ & $\begin{array}{l}\text { Stream- } \\
\text { bed }\end{array}$ & Banks & $\begin{array}{c}\text { Sun } \\
\text { exposure }\end{array}$ & Habitat & $\begin{array}{c}\text { Temperature } \\
\text { water }\left({ }^{\circ} \mathrm{C}\right)\end{array}$ & $\begin{array}{c}\text { Temperature } \\
\text { air }\left({ }^{\circ} \mathrm{C}\right)\end{array}$ \\
\hline L1 & 6859204850715 & 90 & 2.0 & 60 & $\begin{array}{l}\text { tempo- } \\
\text { rary }\end{array}$ & pebbles & mud & sun & field & $\begin{array}{c}17.0 \\
(11.5-22.0)\end{array}$ & $\begin{array}{c}21.5 \\
(11.0-30.5)\end{array}$ \\
\hline L2 & 6954204848065 & 110 & 3.0 & 30 & $\begin{array}{c}\text { perma- } \\
\text { nent }\end{array}$ & pebbles & grass & sun & field & $\begin{array}{c}15.0 \\
(11.5-17.0)\end{array}$ & $\begin{array}{c}23.0 \\
(13.5-32.0)\end{array}$ \\
\hline L3 & 6953004847925 & 110 & 3.0 & 40 & $\begin{array}{c}\text { perma- } \\
\text { nent }\end{array}$ & sand & mud & shadow & wood & $\begin{array}{c}16.0 \\
(13.0-19.0)\end{array}$ & $\begin{array}{c}19.5 \\
(13.0-24.0)\end{array}$ \\
\hline M1 & 6833904863035 & 290 & 8.0 & 40 & $\begin{array}{l}\text { tempo- } \\
\text { rary }\end{array}$ & pebbles & grass & shadow & wood & $\begin{array}{c}17.5 \\
(13.0-23.0)\end{array}$ & $\begin{array}{c}20.5 \\
(12.5-24.0)\end{array}$ \\
\hline M2 & 6829604862865 & 290 & 4.0 & 20 & $\begin{array}{l}\text { tempo- } \\
\text { rary }\end{array}$ & pebbles & mud & sun & wood & $\begin{array}{c}15.5 \\
(12.0-19.0)\end{array}$ & $\begin{array}{c}24.5 \\
(12.5-24.5)\end{array}$ \\
\hline M3 & 6825704866960 & 290 & 5.0 & 50 & $\begin{array}{c}\text { perma- } \\
\text { nent }\end{array}$ & sand & mud & sun & wood & $\begin{array}{c}15.0 \\
(12.0-17.0)\end{array}$ & $\begin{array}{c}20.5 \\
(10.5-28.0)\end{array}$ \\
\hline H1 & 6891304860965 & 555 & 2.0 & 10 & $\begin{array}{c}\text { perma- } \\
\text { nent }\end{array}$ & pebbles & mud & shadow & wood & $\begin{array}{c}12.5 \\
(10.5-14.0)\end{array}$ & $\begin{array}{c}17.0 \\
(11.0-23.0)\end{array}$ \\
\hline $\mathrm{H} 2$ & 6869304862065 & 585 & 1.5 & 50 & $\begin{array}{l}\text { tempo- } \\
\text { rary }\end{array}$ & pebbles & rocks & sun & wood & $\begin{array}{c}13.5 \\
(9.0-18.0)\end{array}$ & $\begin{array}{c}16.0 \\
(11.0-21.0)\end{array}$ \\
\hline $\mathrm{H} 3$ & 6897704861065 & 615 & 3.0 & 15 & $\begin{array}{c}\text { perma- } \\
\text { nent }\end{array}$ & pebbles & mud & shadow & wood & $\begin{array}{c}12.0 \\
(9.0-14.5)\end{array}$ & $\begin{array}{c}18.5 \\
(11.0-24.5)\end{array}$ \\
\hline
\end{tabular}

The present paper reports an analysis of the biology of two southern species of the genus Velia Latreille, 1804, subgenus Plesiovelia Tamanini, 1955, in central Italy (Tuscany): Velia currens (Fabricius, 1794) and $V$. gridellii Tamanini, 1947. Tamanini (1979), in his comprehensive monograph of Italian Gerromorpha and Nepomorpha, reports that all species of Velia are univoltine, but this may not be case. For example, although the congeneric Velia caprai is predominantly univoltine (Brinkhurst, 1959), a second summer generation is occasionally produced, at least in the warmer areas of its range (e.g. Mielewczyk, 1980; Papáček \& Jandová, 2003). There are no specific studies on the two species analysed in the present work. Similarly, although it is claimed that all species of Velia belonging to the subgenus Plesiovelia are dimorphic, with both apterous and macropterous forms (Andersen, 1982), there is no quantitative data available on the two species studied.

There were three main aims to this study. First, to describe, using repeated surveys of nine populations, the life histories of the two species. The populations surveyed were in streams representative of the full range of types of streams inhabited by the species. In particular, the intention was to asses if the two species were uni- or multivoltine and how the time of emergence of adults and nymphs changed with altitude. The second aim was to obtain quantitative information on the occurrence of wing polymorphism, and finally, the degree of co-occurrence of the two species. The work combined direct surveys of natural populations with the construction and analysis of a large database of information on the distribution, occur- rence and incidence of wing polymorphism in the two species.

\section{MATERIAL AND METHODS}

\section{Species and study sites}

The species studied were Velia (Plesiovelia) currens (Fabricius, 1794) and $V$. (P.) gridellii Tamanini, 1947. These species are Alpine-Apenninic elements, belonging to the S-European chorotype (Vigna Taglianti et al., 1993, 1999) and though their distributions extend slightly into the French Maritime Alps (both $V$. gridellii and $V$. currens) and that of $V$. currens into Switzerland (Tessin), Southern Austria and Slovenia (Tamanini, 1979; Andersen, 1995; Protić, 1998), they can be considered to be Italian endemics sensu lato. Both species are typical inhabitants of the surface of streams, and as altitude and associated habitat stability (perennial or seasonal) are claimed as possible determinants of the occurrence of wing polymorphism, the streams selected were located at different altitudes. Specifically, three altitudes were chosen: (a) a low altitude (L), corresponding to $\sim 100 \mathrm{~m} \mathrm{amsl}$; (b) medium altitude (M), corresponding to $\sim 300 \mathrm{~m}$ amsl; and (c) high altitude, at about $600 \mathrm{~m}$ amsl. Three replicated streams were sampled at each altitude $(\Sigma \mathrm{n}=9)$ and all are located in the Province of Florence (Tuscany; Italy). For each stream, the following were recorded: (i) water and air temperature $\left({ }^{\circ} \mathrm{C}\right)$, measured during each survey; (ii) water permanence (temporary, if the site dried up during a survey; permanent, if not). A complete list of the sites sampled together with their major environmental features is provided in Table 1.

Streams were sampled regularly at 15 -day intervals from April to September 2010, with monthly samples taken in October and November 2010 on sunny, calm days. At each sampling site (stream) a transect $10 \mathrm{~m}$ long was established at random. Two different sampling protocols were followed to 

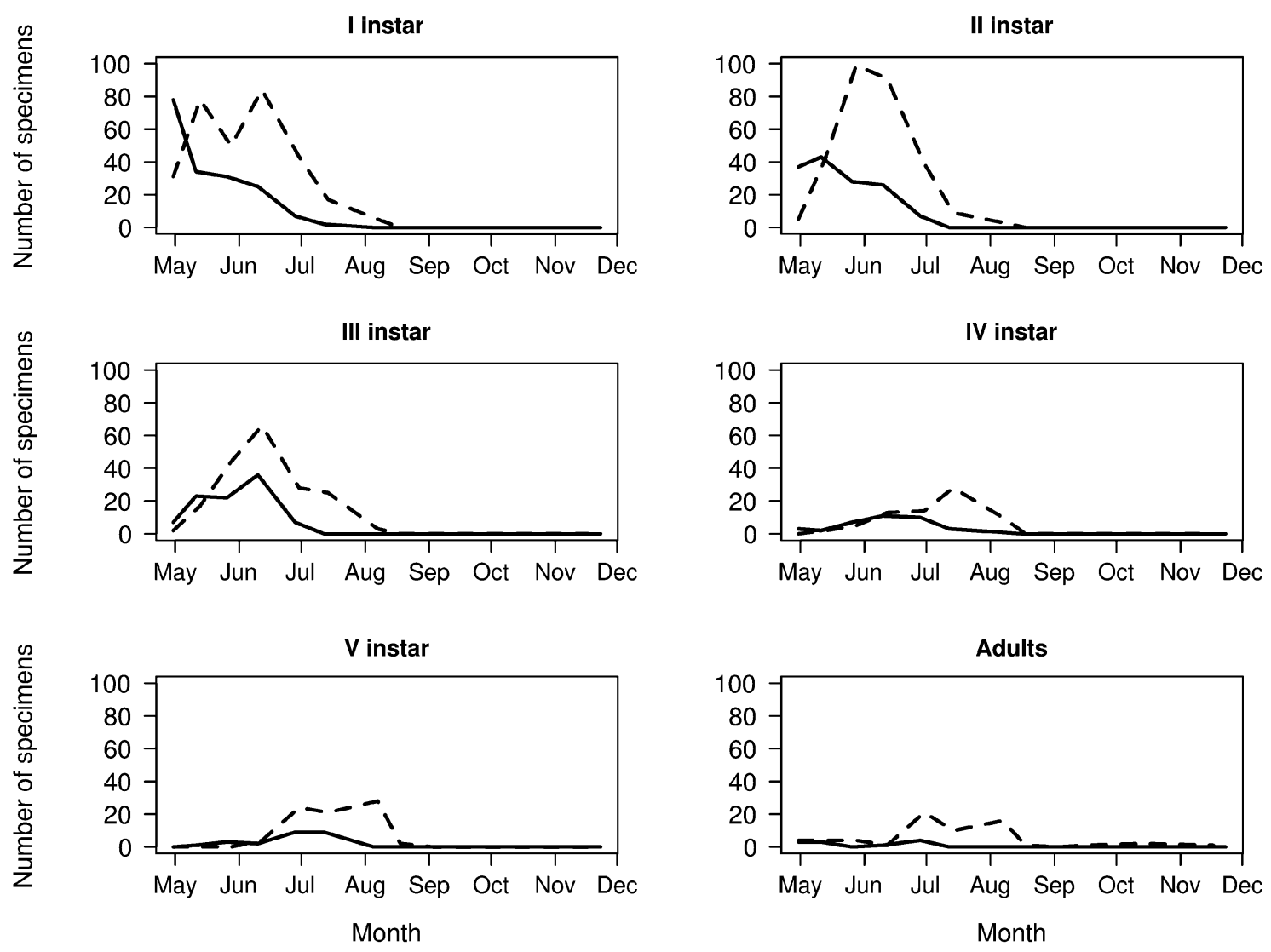

Fig. 1. The numbers of $V$. currens (nymphs and adults) recorded during the study period. Sites L2-L3 - continuous line; Sites M1-M3 - dashed lines.

investigate life histories and wing polymorphism. For lifehistory reconstruction, all specimens (adults + nymphs) collected during a 30-min survey along each transect were examined. Animals were captured in order to identify them and avoid double counting. More time was spent sampling when some of the streams dried up and no swimming specimens were visible. In these cases, dried out sections of the streams were systematically searched for specimens hidden under stones. To quantify the occurrence of wing polymorphism, the sites were sampled until 50 adults or IV/V-instar nymphs were captured. Unambiguously discriminating the presence of wing pads to infer the morph of the earlier stages was difficult and so these stages were not included in the sample. Identification took place directly in the field, using a portable $20 \mathrm{X}$ lens. All the specimens were released where they were collected at the end of the day. Species/stage identification was carried out as follows. Firstly, adult specimens of other coexisting Velia species [i.e. $V$. muelleri Tamanini, 1947 and V. rivulorum (Fabricius, 1775)] were excluded from the samples. Then, $V$. currens and $V$. gridellii were identified based on the shape of the abdomen in lateral view (adult females) and $9^{\text {th }}$ tergite (adult males), in accordance with Tamanini $(1947,1979)$. The identification of the nymphs was based on the length of legs and antennae, and head width (López et al., 1998; Ditrich \& Papáček, 2010b). A reference box with several specimens of all instars belonging to the two species identified in laboratory was also taken into the field for comparison.

\section{Database preparation}

A database comprising previous observations on the two species was created. This was based on lists of specimens preserved in museum and private collections, data previously obtained by the first author and records in the literature. Collections used to create the database were: the Natural History Museum of the University of Florence, Zoological Section (MZUF), the Natural History Museum of Milan (MSNM); the private collections of F. Cianferoni (Florence), J. Damgaard (Copenhagen), A. Mascagni (Florence) and F. Terzani (care of MZUF). Other data were obtained from Tamanini (1947) and Dionisi (2007). Only records for which it was possible to unambiguously locate the sampling site were considered. Each database entry included a record of the locality collected, date, species, number, sex and development of the wings (apterous/macropterous) of the specimens. A total of 294 sites were recorded in the database, covering almost all Italian regions where the two species are present, although the majority came from Central Italy. Some records from South Eastern France were also present. For each site only the presence/absence of macropterous specimens was considered, as information on their abundance was irregular and unreliable. The presence of winged specimens at each site was modelled using logistic regression (Zuur et al., 2009) with altitude (Alt) as the explanatory variable. The statistical significance of this model was determined by comparing (likelihood-ratio test) it with a model not including the factor Alt (intercept-only model). Differences in average altitude of sites where the two species were found (apterous and macropterous specimens pooled), were tested using Welch t-test after square-root transform of data to achieve normality of data (Sokal \& Rohlf, 1995).

To assess co-occurrence patterns between the two species a null-model analysis was performed (Gotelli, 2000). Observed co-occurrence (OCO) was computed as the number of sites where both species were found. Taking "Ngrid" and "Ncurr" as the number of occurrences of $V$. gridellii and $V$. currens, respec- 
I instar

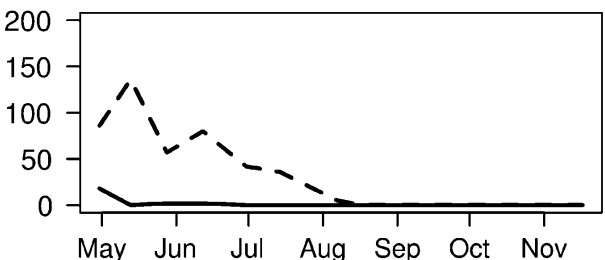

III instar

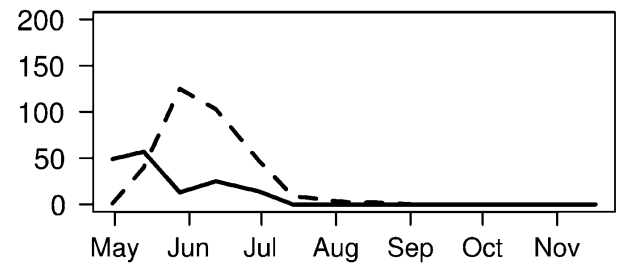

V instar

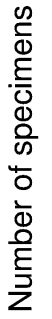

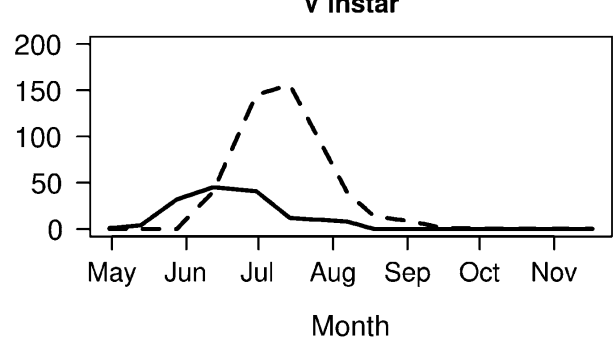

II instar

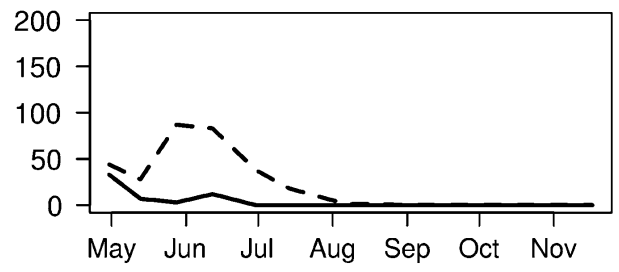

IV instar

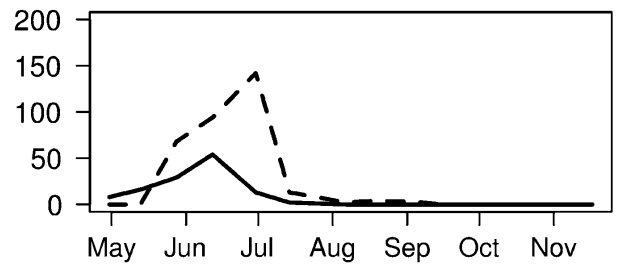

Adults

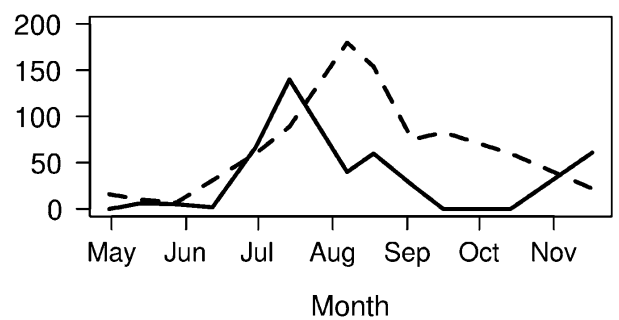

Fig. 2. The numbers of $V$. gridellii (nymphs and adults) recorded during the study period. Site L1 - continuous line; Sites H1-H3 - dashed lines.

tively, in the database, 50000 surrogate datasets were randomly generated, each containing Ngrid and Ncurr occurrences of the two species. The co-occurrence (SCO) of these two species in each of the simulated datasets was computed. If co-occurrence of the two species is random, the OCO value is expected to equal the average SCO, however, if the two species co-occur less frequently than expected by chance, an OCO less than the average SCO is expected. The null hypothesis that $\mathrm{OCO}=\mathrm{SCO}$ was tested counting the number of SCO values less than or equal to OCO (Gotelli, 2000).

All the analyses were carried out using the $\mathrm{R}$ (ver. 2.13.1) software package (R Development Core Team, 2011).

\section{RESULTS}

A total of 1568 specimens (adults + nymphs) of $V$. currens and 3601 of $V$. gridellii were observed during this study, but little co-occurrence between the two species was detected. $V$. currens was detected at low (sites L2-L3) and medium altitudes (M1-M3), but not at the highest sites. In contrast, $V$. gridellii was found at the highest sites $(\mathrm{H} 1-\mathrm{H} 3)$ and at only one of the lower sites (L1). A few specimens of $V$. gridellii were occasionally found at sites L3 and M3 and were not included in subsequent analyses. The numbers of specimen retrieval during the sampling period of the study are shown in Figs 1 and 2 for $V$. currens and $V$. gridellii, respectively. The developmental cycles of the two species also differed in other aspects. In particular, in $V$. currens high numbers of first instar nymphs were followed by progressively lower numbers of later stages (Fig. 1). At medium altitudes, for example, nymph numbers reached a maximum value of 99 (II instar), while the peak for adults never exceeded 21 specimens (Fig. 1). Numbers at lower sites were even lower. This pattern of adult loss was less evident in $V$. gridellii, for which equal or even higher numbers of adults than nymphs were observed (Fig. 2). Within each species, the life histories showed a broad dependence upon altitude, with peaks in abundance of the different stages generally occurring earlier at lower altitudes. The number of individuals observed during the different sampling periods suggests that both species are univoltine. At each site, in fact, for each stage only one developmental peak was observed.

One stream at each altitude ran dry from the end of July to September (Table 1). During this period, a total of 10 $V$. currens (6 males, 4 females) and $94 \mathrm{~V}$. gridellii (47 males, 47 females) specimens were found hidden under stones in the beds of the dried out streams, seemingly in a state of lethargy: they were inactive and did not react initially to mechanical stimuli. Stimulation, which included manipulation for collection, identification and exposure to light lasted about $30 \mathrm{~s}$. All the specimens reverted to a state of activity after a few tens of seconds or minutes.

No macropterous specimens were found among the 3000 individuals $(350 \mathrm{~V}$. currens and $2650 \mathrm{~V}$. gridellii) sampled during the field surveys at the nine study sites and analysis of the database confirmed that macropterous forms occur at very low frequencies. Macropterous specimens of $V$. gridellii were recorded at only 11 out of 192 


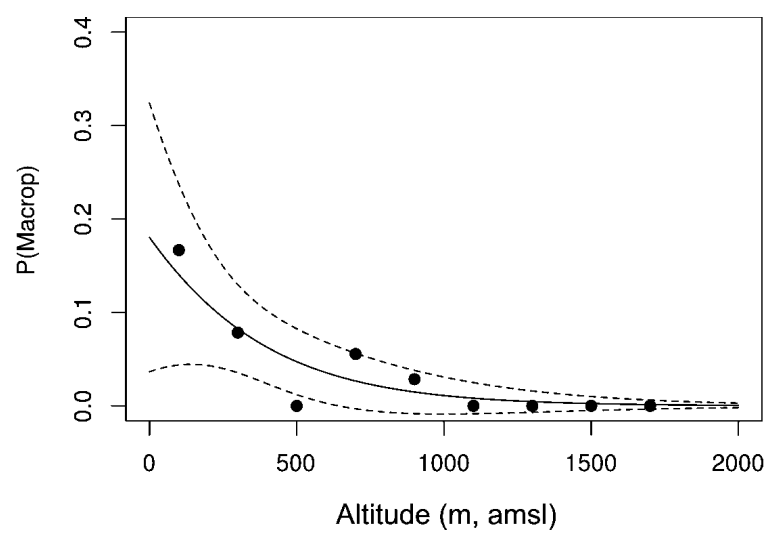

Fig. 3. Probability of recording macropterous individuals $\mathrm{P}$ (Macrop) of $V$. gridellii at sites situated at range of different altitudes. The solid line represents the estimated relationship and the dashed lines the $95 \%$ confidence intervals. Dots represent the observed frequency of macropterous individuals and are the averages for sites in $200 \mathrm{~m}$ ranges in altitude from 100 to $1700 \mathrm{~m}$.

sites (four males, six females and one $\mathrm{V}$-instar nymph). Similar numbers were found for $V$. currens, with a total of six males and 10 females found at 10 out of 138 sites. The frequency of macropterous occurrence in the two species was not statistically different $\left(\chi^{2}=0.108, \mathrm{df}=1\right.$, $\mathrm{P}=0.7427$ ). Furthermore, no evidence of a biased sex ratio was found in macropterous specimens: chi-square test results for a different-from-equal sex ratio were $\mathrm{P}=$ 0.55 and $\mathrm{P}=0.32$ for $V$. currens and $V$. gridellii, respectively.

A significant negative relationship between the occurrence of macropterous specimens and site altitude was detected by regression analysis only for $V$. gridellii (Fig. 3 ). In fact, the model including altitude performed better than the intercept-only model (likelihood-ratio test = $-8.4004, \mathrm{P} \leq 0.005)$. The predicted probability of finding macropterous specimens is at a maximum $(\sim 0.18)$ at low altitudes and then declines rapidly as site altitude increases, becoming almost equal to 0.05 at $500 \mathrm{~m}$. For $V$. currens however, there was no significant relationship between the occurrence of macropterous specimens and altitude. The model including altitude was in fact indistinguishable from the intercept-only model (likelihood-ratio test $=-2.5442, \mathrm{P}>0.1$ ). On average, $V$. currens (all specimens pooled) occurred at slightly lower altitude sites (mean altitude $=452 \mathrm{~m}$, with 509 and $400 \mathrm{~m}$ being their upper and lower $95 \% \mathrm{CI}$ ) than $V$. gridellii (mean altitude $=526 \mathrm{~m}$, with 585 and 470 upper and lower 95\% CI) although this difference was not statistically significant (Welch t-test $=-1.8081, \mathrm{df}=316.30, \mathrm{P}>0.07$ ).

Based on the evidence from the database, the two species co-occurred less frequently than expected by chance. The observed co-occurrence (OCO) was in fact only 25 (out of 294 sites), which is approximately half of the mean simulated value $(\mathrm{SCO}=53.05 \pm 4.84 \mathrm{SE})$. The null hypothesis that $\mathrm{OCO}=\mathrm{SCO}$ could safely be rejected since only 14 of the 50000 simulated SCOs were less than or equal to $\mathrm{OCO}$, giving $\mathrm{P}=0.00028$.

\section{DISCUSSION}

The results of this study showed no clear evidence of multivoltinism in either of the two species. Generally there was only one peak in numbers in each of the life stages (I-V-instar nymphs and adults), with the only exception being $V$. gridellii at the lower altitude sites. This finding agrees with previous observations by Tamanini (1947, 1979), who claimed that univoltinism may be the norm for all Velia species in northern Italy, although the possibility that different generations may coexist in more southern populations was not excluded. However, if these two species are not multivoltine then the laying and/or hatching of their eggs must have occurred over a long period of time as early-instar nymphs and adults co-occurred over much of the period of this study. First-instar nymphs, for instance, were observed up to mid July, when the peak number of mature adults occurred. However, it cannot be completely ruled out that these late nymphs belonged to a second generation mixed with the previous one (e.g. Murray \& Giller, 1991; Ditrich \& Papáček, 2009c). The second autumn peak observed in $V$. gridellii is unlikely to have been due to the production of a second generation as it was not preceded by a similar pattern in nymph abundance. In fact, this peak appeared after the summer reduction in activity, when most of the streams dried up and is, therefore, likely to be related to the resumption of activity of previously aestivating adults. This point will be further discussed below. In this study, sampling started during spring and no information was collected on the behaviour of this species during the winter. A further development of this study should thus focus more closely on this subject. In particular, it is important to check whether females in autumn and/or spring contain chorionated eggs, which would indicate the overwintering of reproductive females and the possibility overwintering in both the egg and adult stages. This way of overwintering, detected in $V$. caprai and $V$. saulii (see Ditrich \& Koštál, 2011), seems to be a crucial aspect of the distribution of these species in northern regions, verifying its occurrence in Mediterranean species of this genus would be of great interest.

Nymphal development was presumably affected by temperature: faster developmental rates were observed at low/medium altitudes, where water and air were generally warmer. This finding agrees with previous observations on the Central European species $V$. caprai (Murray \& Giller, 1991; Ditrich \& Papáček, 2009b), other species of gerrids (e.g. Spence \& Andersen, 1994; Pfenning \& Poethke, 2006) and more generally what is known regarding insect development (e.g. Chown \& Nicolson, 2004). Caution must be exercised, however, as temperature is only one of the possible factors affecting nymphal development that changes with altitude; other possibilities might be population density and/or prey availability (Bronmark et al., 1985; Blanckenhorn, 2006; Ditrich \& Papáček, 2010b). Due to the different altitudinal distributions of the two species, it is difficult to separate species differences from those induced by environmental factors. 
In $V$. currens, high numbers of first instar nymphs were followed by progressively lower numbers of later stages, a pattern broadly expected due to natural mortality during the different stages. A different pattern however, was observed in $V$. gridellii, where equal or even higher numbers of adults than nymphs were observed. The reasons for this unexpected pattern are not yet known but there are two plausible explanations. It is possible that there is an influx of adult specimens from upper sections of the same streams (Ditrich \& Papáček, 2009b). This point is consistent with the fact that this pattern was more pronounced in the lower stream where this species was found. Sampling error (e.g. due to the lower mobility and catchability of nymphs than adults) as a cause however cannot be completely ruled out.

The differences in altitude at which the two species were found constitute an important discussion point. In our field samples $V$. gridellii occupied higher altitudes than $V$. currens. This finding not only contrasts with previous observations, showing that both species may be present irrespective of altitude (see Bacchi \& Rizzotti Vlach, 2007), but also with evidence from our database, where no difference in altitudinal range was detected. The observed separation of the two species should, at least in part, be attributed to factors other than altitude, or the environmental determinants directly correlated with it, such as temperature. Altitudinal differences in the distributions of the specimens sampled are, in our opinion, most likely to be a consequence of secondary effects of a more general mechanism separating the two species. Of course, these differences may also be due to an undetected bias in the selection of sampling sites. A spatial segregation of the two species was detected by nullmodel analysis, showing that the two species co-occurred less frequently than expected by chance. However, the actual mechanism behind this pattern remains uncertain and may range from competitive exclusion, to habitatdriven segregation based on an unknown environmental factor. Inferring such effects from the observed pattern without additional data is, however, impossible at this stage (Gotelli, 2000) and may represent a further goal for future research. Whereas it is known that different species of Gerromorpha may show spatial partitioning due to differences in habitat features (see, for example, Andersen, 1982; Karaouzas \& Gritzalis, 2006; Ditrich et al., 2008), no information exists on the competition among these species of aquatic Heteroptera, although competitive interactions among sympatric corixid species are documented (Vepsäläinen, 1978b). A caveat to this discussion is the reliability of the database records. Although analyses of data based on voucher specimens or databases compiled from literature sources is increasingly regarded as a useful and sometimes fundamental tool in biodiversity research (see, for example, Schlick-Steiner et al., 2003), the reliability of collections has to be carefully checked before any firm conclusions can be drawn. The results of the analysis of co-occurrence may be trusted if it is true that both species were searched for equally, at all sites (that is to say that collectors did not selectively catch one species or the other). In fact, we are confident that this assumption was fulfilled with respect to our database. Care was taken to directly ask the owners of the personal collections for confirmation in this regard. This was also clearly stated in published material, as well as for the museum collections, for which a careful inspection of all notes, sketches and related issues was carried out.

The occurrence of macropterous specimens was very low in both species, even lower than that reported for other Velia species (e.g. Brinkhurst, 1959b). In database samples, although winged morphs occurred with a similar frequency in both species, a significant dependency on altitude was found for $V$. gridellii but not $V$. currens. The observed altitude-related effect broadly supports the hypothesis that macropterism may be linked to environmental determinants, and presumably to those related with habitat predictability and stability. The absence of macropterous specimens in our field samples may simply be due to the low incidence of macropterism in these species. Despite the high total number of individuals observed, the number of sites visited was limited (three for each altitude level, making a total of nine) and the probability of finding a "positive" site (i.e. one with macropterous individuals) at each level was very low. Moreover collecting is usually associated with a positive bias towards rare morphs, so that the relative numbers of macropters in collections might be greater than in nature.

An important point worth noting was the presence, during summer, of adults of both sexes hidden under the stones in dried-up streams. These specimens were seemingly aestivating in a state of lethargy, as indicated by the fact that they remained completely immobile and did not initially responded to external stimuli when uncovered. Aestivation has been described before in Gerridae (Hauser, 1982) and hibernation is frequently recorded in waterbugs, including Velia spp. (e.g. Brinkhurst, 1959b; Murray \& Giller, 1991; Ditrich \& Papáček, 2009a). Aestivation probably also occurs in $V$. caprai, as firstly suggested by (Ditrich, 2005), and partly confirmed by Ditrich \& Papáček (2008) and Ditrich \& Koštál (2011). However, it is unclear if the aestivation observed in Velia spp. is really a true diapause (with arrested gonad development) or just some kind of quiescence. An ad-hoc study on the state of gonads during the summer would help to resolve this issue. The presence of adult Velia spp. hiding under stones in dried-up stream-beds, during summer and early autumn, has been observed by P. Štys (pers. comm.) on several Greek islands, although these adults were not lethargic. Finally, Bronmark et al. (1985) after a markrecapture study of $V$. caprai populations in Sweden conclude that only a small fraction of the populations was active at any one time, suggesting a great number of specimens remained hidden. This kind of behaviour may be adaptive during summer droughts (Southwood, 1962) as it makes it more likely they will survive until the onset of the autumn rains that rejuvenate the streams. This was particularly evident for $V$. gridellii at the lower sites, where adults reappeared in autumn, having previously disappeared during the summer months. 
It could therefore be hypothesized that the ability to aestivate may make it less advantageous to produce winged specimens and account for the low rate of occurrence of macropterism in these species. In fact, macropterous specimens, although able to travel long distances in search of a suitable environment when faced with unfavourable conditions (Andersen, 1982), generally incur a cost in terms of reduced fecundity, at least in females (see the review by Zenna \& Denno, 1997), and so it is likely that a trade-off exists between the benefits (if any) of macropterism and the associated cost to reproduction. It is important to stress that the ability of macropterous specimens to fly has never been verified in this species and at present it is only possible to speculate what the possible benefits of being able to disperse by flying might be. The ability to endure unfavourable conditions by aestivating may reduce the advantage associated with producing winged forms. Furthermore, some Velia species can crawl out of water (e.g. Andersen, 1982), the most striking example of which is the case of $V$. caprai, as reported by Ditrich \& Papáček (2009b, 2010a). They revealed using both mark-recapture in the field and laboratory experiments that this species surprisingly can walk over land for up to tens of meters. Individuals of both $V$. currens and $V$. gridellii were also occasionally observed walking short distances over land during the present study, but the maximum distance travelled was not recorded. Therefore, aestivation coupled with an ability to walk out of water may partly act as a substitute for dispersion by flight.

In conclusion, the results presented in this paper help to shed some light on the life-history traits of these two Velia species, for which very little is known. Details of the incidence of macropterism add to existing knowledge on this intriguing aspect of Gerromorphan biology (Andersen, 1982) and corroborate previous findings on its determinants. Furthermore, the findings on spatial segregation of the two species pose new questions about their ecology and highlight the need for further investigations to clarify the causes of such a pattern. Finally, apart from improving our understanding of the ecology and behavioural traits of these species, a better understanding of their biology may help us conserve these organisms, for which the combined effects of restricted distribution (endemic to Italy s. 1.) and increasing effect of humans upon freshwater habitats (EEA, 2010) pose serious threats to their survival.

ACKNOWLEDGEMENTS. Thanks are due to F. Terzani and S. Rocchi (MZUF) for providing specimens for this work and L. Bartolozzi (MZUF) and M. Pavesi (MSNM) for allowing the first author to study museum collections. R. Dionisi (Rome, Italy) kindly provided further useful data from his own samples. Many thanks are also due to D. Samancioglu, A. Fortunati and G. Mazza (Florence, Italy) for their help during the fieldwork. We are grateful to P. Štys (Charles University, Prague, Czech Republic) and two anonymous referees, for their suggestions, which contributed to improve the manuscript.

\section{REFERENCES}

ANDERSEN N.M. 1973: Seasonal polymorphism and developmental changes in organs of flight and reproduction in bivoltine pondskaters (Hem. Gerridae). Entomol. Scand. 4: $1-20$.

Andersen N.M. 1982: The semiaquatic bugs (Hemiptera, Gerromorpha). Phylogeny, adaptations, biogeography, and classification. Entomonograph 3: 1-455.

Andersen N.M. 1993: The evolution of wing polymorphism in water striders (Gerridae): a phylogenetic approach. Oikos 67: 433-443.

Andersen N.M. 1995: Gerromorpha. In Aukema B. \& Rieger C. (eds): Catalogue of the Heteroptera of the Palaearctic Region. Vol. 1. Enicocephalomorpha, Dispocoromorpha, Nepomorpha, Gerromorpha and Leptopodomorpha. The Netherlands Entomological Society, pp. 77-114.

BaCchi I. \& RizzotTi Vlach M. 2007: Insecta Heteroptera Nepomorpha and Gerromorpha. In Ruffo S. \& Stoch F. (eds): Checklist and Distribution of the Italian Fauna. Mem. Mus. Civ. Stor. Nat. Verona 16[2006]: 147-149 + CD-ROM.

BLANCKENHORN W.U. 2006: Divergent juvenile growth and development mediated by food limitation and foraging in the water strider Aquarius remigis (Heteroptera: Gerridae). $J$. Zool. 268: 17-23.

BRINKHURST R.O. 1959: Alary polymorphism in the Gerroidea (Hemiptera Heteroptera). J. Anim. Ecol. 28: 211-230.

Chown S.L. \& Nicolson S.W. 2004: Insect Physiological Ecology: Mechanisms and Patterns. Oxford University Press, New York, 243 pp.

Dionisi R. 2007: Gli Eterotteri acquatici del Lazio (Heteroptera: Gerromorpha, Nepomorpha). Boll. Ass. Rom. Entomol. 62: 41-100.

DitRICH T. 2005: Životni cyklus a vývoj reprodukčnich orgánů hladinatky Velia caprai Tamanini, 1947 (Hemiptera: Heteroptera: Veliidae). [Life history and gonad development of a water cricket Velia caprai Tamanini, 1947 (Hemiptera: Heteroptera: Veliidae).] MSc. thesis, Faculty of Education, University of South Bohemia, 139 pp. [in Czech, English abstr.].

Ditrich T. \& PAPÁČEK M. 2008: Neobvyklá životní strategie u semiakvatických ploštic: bionomie Velia caprai Tamanini 1947 (Heteroptera: Gerromorpha: Veliidae). [An unusual life history within semiaquatic bugs: bionomy of Velia caprai Tamanini 1947.] In Bryja J., Nedvěd O., Sedláček F. \& Zukal J. (eds): Zoologické dny České Budějovice 2008. Sborník abstrakti̊ z konference 14.-15. února 2008 [Zoological Days České Budějovice 2008, Proceedings of Conference from 14-15 February 2008]. pp. 44-45 [in Czech].

Ditrich T. \& PAPÁČEK M. 2009a: Effective strategy of the overwintering of semiaquatic bugs: Overwintering of Velia caprai (Heteroptera: Gerromorpha: Veliidae). J. Nat. Hist. 43: 529-543.

Ditrich T. \& PAPÁČEK M. 2009b: Correlated traits for dispersal pattern: Terrestrial movement of the water cricket Velia caprai (Heteroptera: Gerromorpha: Veliidae). Eur. J. Entomol. 106: 551-555.

Ditrich T. \& PAPÁČEK M. 2009c: A question of voltinism of Microvelia reticulata (Veliidae) and Mesovelia furcata (Mesoveliidae) (Heteroptera: Gerromorpha) in Central Europe. 21st SIEEC, České Budějovice, June 28 - July 3, 2009. University of South Bohemia, České Budějovice, pp. $20-23$.

Ditrich T. \& PAPÁČEK M. 2010a: Extraordinary life history in semiaquatic bugs: case of Velia caprai. Proceedings of the 4th Meeting of IHS. Tianjin, China, pp. 38-39.

Ditrich T. \& PAPÁČEK M. 2010b: Effect of population density on the development of Mesovelia furcata (Mesoveliidae), Microvelia reticulata and Velia caprai (Veliidae) (Heteroptera: Gerromorpha). Eur. J. Entomol. 107: 579-587. 
Ditrich T. \& KošŤÁL V. 2011: Comparative analysis of overwintering physiology in nine species of semi-aquatic bugs (Heteroptera: Gerromorpha). Physiol. Entomol. 36: 261-270.

Ditrich T., PApÁČEK M. \& Broum T. 2008: Spatial distribution of semiaquatic bugs (Heteroptera: Gerromorpha) and their wing morphs in a small scale of the Pohořský Potok stream spring area (Novohradské Hory Mts.). Silva Gabreta 14: 173-178.

Ditrich T., PAṕ́č́tek M. \& Heino M. 2011: The latitudinal uniformity of the unique life history of Velia caprai (Heteroptera: Veliidae) and notes to the pre-overwintering period of selected water striders (Heteroptera: Gerridae). Entomol. Fenn. 22: 106-112.

EEA 2010: The European Environment - State and Outlook 2010: Synthesis. European Environment Agency, Copenhagen, $222 \mathrm{pp}$.

Gotelli N.J. 2000: Null model analysis of species cooccurrence patterns. Ecology 81: 2606-2621.

Gotelli N.J. \& Graves G.R. 1996: Null Models in Ecology. Smithsonian Institution Press, Washington, DC, 368 pp.

HAUSER R. 1982: Untersuchungen zu Voltinismus und Flügelpolymorphismus beim Wasserläufer Gerris lacustris (Hemiptera: Gerridae). Rev. Suisse Zool. 89: 903-917.

KaraouZas I. \& Gritzalis K. 2006: Local and regional factors determining aquatic and semi-aquatic bug (Heteroptera) assemblages in rivers and streams of Greece. Hydrobiologia 573: $199-212$.

López T., Costas M. \& Vásquez Á. 1998: Ciclo biológico y estadios juveniles de Aquarius cinereus (Puton, 1869) (Heteroptera: Gerridae). Boln. Asoc. Esp. Entomol. 22: 23-31.

MielewCZYK S. 1980: Zur Ökologie, Biologie und Morphologie von Velia saulii Tam. und V. caprai Tam. (Heteroptera, Veliidae). Ann. Zool. (Warszawa) 35: 285-305.

Mitis H. von 1937: Ökologie und larventwicklung der mitteleuropäischen Gerris Arten (Het). Zool. Jb. 69: 337-372.

MurajI M. \& NakasujI F. 1988: Comparative studies on life history traits of three wing dimorphic water bugs, Microvelia spp. Westwood (Heteroptera: Veliidae). Popul. Ecol. 30: 315-327.

Muraji M., Miura T. \& NakasujI F. 1989: Phenological studies on the wing dimorphism of a semi-aquatic bug, Microvelia douglasi (Heteroptera: Veliidae). Res. Popul. Ecol. 31: $129-138$.

MurRay A.M. \& Giller P.S. 1991: Life history and overwintering tactics of Velia caprai Tam. (Hemiptera: Veliidae) in Southern Ireland. Aquat. Insects 13: 229-243.

PAPÁČEK M. \& JANDOVÁ L. 2003: Extreme variability of life history in the water cricket Velia caprai, Tamanini 1947 (Heteroptera: Gerromorpha: Veliidae): the study under the environmental conditions of the Novohradské hory Mts. In Papáček M. (ed.): Biodiversity and Environmental Conditions of the Novohradské hory Mountains. University of South Bohemia and Institute of Entomology, Biology Centre, ASCR, České Budějovice, pp. 149-162 [in Czech, English abstr.].

Pfenning B. \& Poethke H.J. 2006: Variability in the life history of the water strider Gerris lacustris (Heteroptera: Gerridae) across small spatial scales. Ecol. Entomol. 31: 123-130.

Pfenning B., Poethke H.J. \& Hovestadt T. 2007: Dealing with time constraints on development: the effect of food availability. Ecol. Entomol. 32: 273-278.

Pfenning B., Gerstner S. \& Poethke H.J. 2008: Alternative life histories in the water strider Gerris lacustris: time constraint on wing morph and voltinism. Entomol. Exp. Appl. 129: $235-242$.
Protić L. 1998: Catalogue of the Heteroptera Fauna of Yugoslav Countries. Part one. Vol. 38. Natural History Museum, Belgrade, $215 \mathrm{pp}$

R Development Core Team 2011: R: A Language and Environment for Statistical Computing. R Foundation for Statistical Computing, Vienna, Austria. URL http://www.R-project.org/.

Schlick-STeiner B.C., Steiner F.M. \& SchÖDl S. 2003: A case study to quantify the value of voucher specimens for invertebrate conservation: ant records in Lower Austria. Biodivers. Conserv. 12: 2321-2328.

Socha R. \& Zемек R. 2003: Wing morph-related differences in the walking pattern and dispersal in a flightless bug, Pyrrhocoris apterus (Heteroptera). Oikos 100: 35-42.

SoKal R.R. \& Rohlf F.J. 1995: Biometry: The Principles and Practice of Statistics in Biological Research. Freeman, New York, $887 \mathrm{pp}$.

SoutHWoOD T.R.E. 1962: Migration of terrestrial arthropods in relation to habitat. Biol. Rev. Cambridge Philos. Soc. 37: 171-211.

SPENCE J.R. 1989: The habitat templet and life history strategies of pond skaters (Heteroptera: Gerridae): reproductive potential, phenology, and wing dimorphism. Can. J. Zool. 67: 2432-2447.

Spence J.R. \& ANDERSEN N.M. 1994: Biology of water striders interactions between systematics and ecology. Annu. Rev. Entomol. 39: 101-128.

TAMANINI L. 1947: Contributo ad una revisione del genere Velia Latr. e descrizione di alcune specie nuove (Hemiptera, Heteroptera, Veliidae). Mem. Soc. Entomol. Ital. 26: 17-74.

TAMANINI L. 1979: Eterotteri acquatici (Heteroptera: Gerromorpha, Nepomorpha). Guide per il Riconoscimento delle Specie Animali delle Acque Interne Italiane. $\mathrm{CNR}, \mathrm{AQ} / 1 / 43,6$ : $1-106$.

VEPSÄLÄINEN K. 1973: The distribution and habitats of Gerris Fabr. species (Heteroptera, Gerridae) in Finland. Ann. Zool. Fenn. 10: 419-444.

VEPSÄLÄINEN K. 1974: The life cycles and wing lenghts of Finnish Gerris Fabr. species (Heteroptera, Gerridae). Acta. Zool. Fenn. 141: 1-73.

VEPSÄLÄINEN K. 1978a: Wing dimorphism and diapause in Gerris: determinations and adaptive significance. In Dingle $\mathrm{H}$. (ed.): Evolution of Insect Migration and Diapause. Springer, New York, pp. 218-253.

VEPSÄLÄINEN K. 1978b: Coexistence of two competing corixid species (Heteroptera) in an archipelago of temporary rock pools. Oecologia 37: 177-182

Vigna Taglianti A., Audisio P.A., Belfiore C., Biondi M., Bologna M.A., Carpaneto G.M., De Biase A., De Felici S., Piattella E., Racheli T., Zapparoli M. \& Zoia S. 1993: Riflessioni di gruppo sui corotipi fondamentali della fauna W-paleartica ed in particolare italiana. Biogeographia - Lav. Soc. Ital. Biogeog. 16[1992]: 159-179.

Vigna Taglianti A., Audisio P.A., Biondi M., Bologna M.A., Carpaneto G.M., De Biase A., Fattorini S., Piattella E., Sindaco R., Venchi A. \& Zapparoli M. 1999: A proposal for a chorotype classification of the Near East fauna, in the framework of the Western Palearctic region. BiogeographiaLav. Soc. Ital. Biogeog. 20: 31-59.

Zera A.J. \& Denno R.F. 1997: Physiology and ecology of dispersal polymorphism in insects. Annu. Rev. Entomol. 42: 207-231.

Zuur A.F., Ieno E.N, Walker N.J., Saveliev A.A., Smith G.M. 2009: Mixed Effects Models and Extensions in Ecology with $R$. Springer, New York, $574 \mathrm{pp}$.

Received January 2, 2012; revised and accepted March 9, 2012 